\title{
Intervention for promoting intake of fruits and vegetables in Brazilians: a randomised controlled trial
}

\author{
Raquel de Deus Mendonça ${ }^{1,2}$, Sueli Aparecida Mingoti ${ }^{3}$, \\ Maria Flávia Gazzinelli Bethony ${ }^{4}$, Miguel Angel Martinez-Gonzalez ${ }^{5,6}$, \\ Maira Bes-Rastrollo ${ }^{5}$ and Aline Cristine Souza Lopes ${ }^{1, *}$ \\ 'Department of Nutrition, Universidade Federal de Minas Gerais, Avenue Alfredo Balena, 190, Belo Horizonte, MG \\ 30190-100, Brazil: ${ }^{2}$ CAPES Coordination for the Improvement of Higher Education Personnel Foundation, Ministry of \\ Education of Brazil, Setor Bancário Norte (SBN), Quadra 2, Edifício CAPES, Brasília, DF, Brazil: ${ }^{3}$ Department of \\ Statistics, Universidade Federal de Minas Gerais, Belo Horizonte, MG, Brazil: ${ }^{4}$ Department of Applied Nursing, \\ Universidade Federal de Minas Gerais, Belo Horizonte, MG, Brazil: ${ }^{5}$ Department of Preventive Medicine and Public \\ Health, University of Navarra, Pamplona, Navarra, Spain: ${ }^{6}$ Department of Nutrition, Harvard TH Chan School of \\ Public Health, Boston, MA, USA
}

Submitted 17 November 2020: Final revision received 21 September 2021: Accepted 18 October 2021: First published online 12 November 2021

\begin{abstract}
Objective: To evaluate the effectiveness of a nutritional intervention to promote fruit and vegetable (FV) intake.

Design: A randomised controlled community trial was conducted to evaluate the effectiveness of a 7-month nutritional intervention and to promote FV intake, separately and together. All participants attended physical exercise sessions. The intervention was based on the transtheoretical model and Paulo Freire's pedagogy. The interventions included group educational sessions, motivational cards and informational materials. The primary outcome was a change in FV intake $(\mathrm{g} / \mathrm{d})$, and secondary outcomes included stages of change, self-efficacy, decisional balance and knowledge on FV. All data were collected face-to-face; and FV intake was assessed using a validated brief questionnaire.

Setting: Health promotion services of Brazilian Primary Health Care.

Participants: 3414 users of Brazilian Primary Health Care (1931 in the control group and 1483 in the intervention group (IG)).

Results: At baseline, the average daily FV intake was 370.4 g/d (95\% CI 364.2, 376.6). The increase in FV intake $(23.4 \mathrm{~g} / \mathrm{d} ; 95 \% \mathrm{CI} 6.7,40.0)$ and fruit intake $(+17.3 \mathrm{~g} / \mathrm{d} ; 95 \% \mathrm{CI} 5 \cdot 1,29 \cdot 4 ; P=0.01)$ was greater in the IG among participants in the lowest baseline intake. Participants in the IG also showed progression in the stages of change $(P<0.001)$, increased self-efficacy $(P<0.001)$ and improved knowledge of FV crops $(P<0 \cdot 001)$.

Conclusions: The nutritional intervention was effective in increasing FV intake and fruits intake among individuals with a lower intake at baseline and in maintaining $\mathrm{FV}$ intake among those who reported consuming FV as recommended (400 g/d).
\end{abstract}

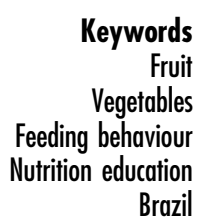

Suboptimal fruit and vegetable (FV) intake is one of the 10 main contributors to the global burden of disease ${ }^{(1)}$. FV intake is associated with a lower risk of mortality and helps to prevent conditions such as obesity, diabetes, CVD, cancer and mortality ${ }^{(1-3)}$. However, an inadequate FV intake is notable globally, and the intake of FV is generally low in relation to the recommended amount (>400 g or 5 servings per day) $)^{(1)}$.

According to the European Union, approximately $12 \%$ of adults consume 5 servings ( $\cong 400 \mathrm{~g}$ ) of FV daily, and people with higher education levels tend to eat more FV than those with lower education levels ${ }^{(4)}$. In the USA, only $12 \cdot 2 \%$ and $9.3 \%$ of adults consume FVs, respectively, in accordance with the recommended amounts ${ }^{(5)}$. In Brazil, a National Health Survey showed that only $37 \cdot 3 \%$ of adults consumed 5 servings of FV per day ${ }^{(6)}$. One study, that assessed the food patterns in 18 countries, showed that the participants consumed an average of 3.8 servings ( $\cong 304 \mathrm{~g}$ ) of $\mathrm{FV}$ per day; and $\mathrm{FV}$ intake in low-income and lower-middle-income countries were $2 \cdot 1$ and 3.2 servings per day ( $\cong 168 \mathrm{~g}$ and $256 \mathrm{~g}$ of FV), respectively ${ }^{(7)}$. 
WHO suggests performing effective, low-cost interventions that aim to increase FV intake ${ }^{(1)}$. Promising results have been documented in a number of studies ${ }^{(8-10)}$. However, most trials have been conducted in developed countries, and intervention studies have rarely been conducted in poor communities. A systematic review of interventions and programmes, promoting fruit and/or vegetable intake in adults, showed that only 5 out of 44 studies included low-income participants ${ }^{(11)}$. Similarly, in another systematic review of interventions, based on feeding behaviour theories, 7 out of 34 studies were conducted among minority and low-income populations ${ }^{(12)}$. Systematic reviews have also shown that few papers reported the theories and methods used in the interventions ${ }^{(11-13)}$. Additionally, most of the nutritional interventions did not examine the individual's perception of intake ${ }^{(14)}$.

Furthermore, few studies have been conducted in the health services ${ }^{(15)}$, which might affect the sustainability of outcomes. The promotion of adequate and healthy food, including the intake of $\mathrm{FV}$, is the focus of several Brazilian public policies. This includes the implementation of the Food Guide, which is one of the priorities of health services, mainly in Primary Health Care. However, it is still necessary to direct local strategies for promoting the intake of $\mathrm{FV}$, and respecting the food culture of each region in Brazil $^{(16)}$

Therefore, this study was designed to promote FV intake and was based on the perceptions of low-income participants regarding their intake habits and using theories. Thus, the study aimed to evaluate the effectiveness of nutritional interventions in promoting $\mathrm{FV}$ intake among participants of the health promotion services from the Brazilian Primary Health Care.

\section{Methods}

\section{Study design and setting}

This study was a community randomised controlled trial, conducted to promote $\mathrm{FV}$ intake in a representative sample of participants from the Health Academy Programme (HAP) in Belo Horizonte, Minas Gerais, Brazil, between February 2013 and March 2015.

Belo Horizonte is the capital of the Minas Gerais state, located in Southeast Brazil. It is the sixth most populous city in the country, with an estimated population of 2.5 million inhabitants and a high Human Development Index value of $0 \cdot 810^{(17)}$. For health action planning, the city is divided into 9 administrative regions.

This municipality has focused on strategies to enhance public health policies and inter-sector actions for health promotion in more socially vulnerable populations, with a heavy investment in primary care. For this, it created the HAP, in 2006, as a health programme integrated with the Primary Health Care network of the national healthcare system $^{(18)}$. HAP consists of a set of facilities with infrastructure, equipment and qualified professionals to guide the physical activity and the promotion of healthy dietary habits, at no cost to participants.

\section{Study population}

From the 50 units of HAP operating in Belo Horizonte at the time of sampling, 42 centres were at eligible locations with regard to community health vulnerability. The eligibility criteria for centres were: located in areas with high Health Vulnerability Indexes (priority given for the implementation of HAP by the municipality), had morning operation hours and had not participated in nutrition intervention activities in the past 2 years. The Health Vulnerability Index is a composite index that incorporates aspects of sanitation, housing, education, income and health. The Health Vulnerability Index is a combination of different variables within an indicator that may be used to summarise relevant information that reflects intra-urban inequalities. The indicators represent basic sanitation, housing, income and health, and are scored from 0 to 1 , and the closer the value is to $1(1 \cdot 0)$, the greater the health vulnerability of the population; very low ( 0 to $0 \cdot 200)$, low ( 0.201 to $0.300)$, medium (0.301 to 0.400$)$, high (0.401 to 0.500$)$ or very high $(0.501 \text { to } 1)^{(19,20)}$.

A total of 18 centres were randomly selected and consisted of 2 centres per administrative district. The centres were randomly divided into the intervention group (IG) or control group (CG), randomised to provide a power of $80 \%$ to detect a change in FV intake in the IG. All participants were not blinded to the group allocations. These centres were representative of the HAP programme with a $95 \% \mathrm{CI}$ and $<1.4 \%$ error based on an estimation of the HAP population proportion (sex, age, education level). Details of the sampling process are available in a previous paper $^{(19)}$.

Of the HAP centres sampled, 3778 users (age, $\geq 20$ years) participated in routine service activities (such as physical exercise programmes) in the preceding month. Pregnant women and individuals with cognitive difficulties (preventing attentive research participation) were excluded from the study. Considering $6.6 \%$ ( $n$ 252) exclusions and $3.0 \%$ ( $n$ 112) refusals, 3414 individuals participated in this study, with a corresponding study response rate of $90 \cdot 4 \%{ }^{(19)}$. Figure 1 shows a flowchart of the study design.

\section{Nutritional intervention}

Individuals in the IG and CG took part in routine activities of the provided service, which included 1-h physical activity sessions, 3 times a week. Additionally, a nutritional intervention was performed with the IG to promote FV intake during the 7-month period. The participants in the CG did not receive any intervention specific to $\mathrm{FV}$ intake during the same period $^{(20)}$.

The intervention for promoting FV intake was developed by an interdisciplinary team comprising nutritionists, 


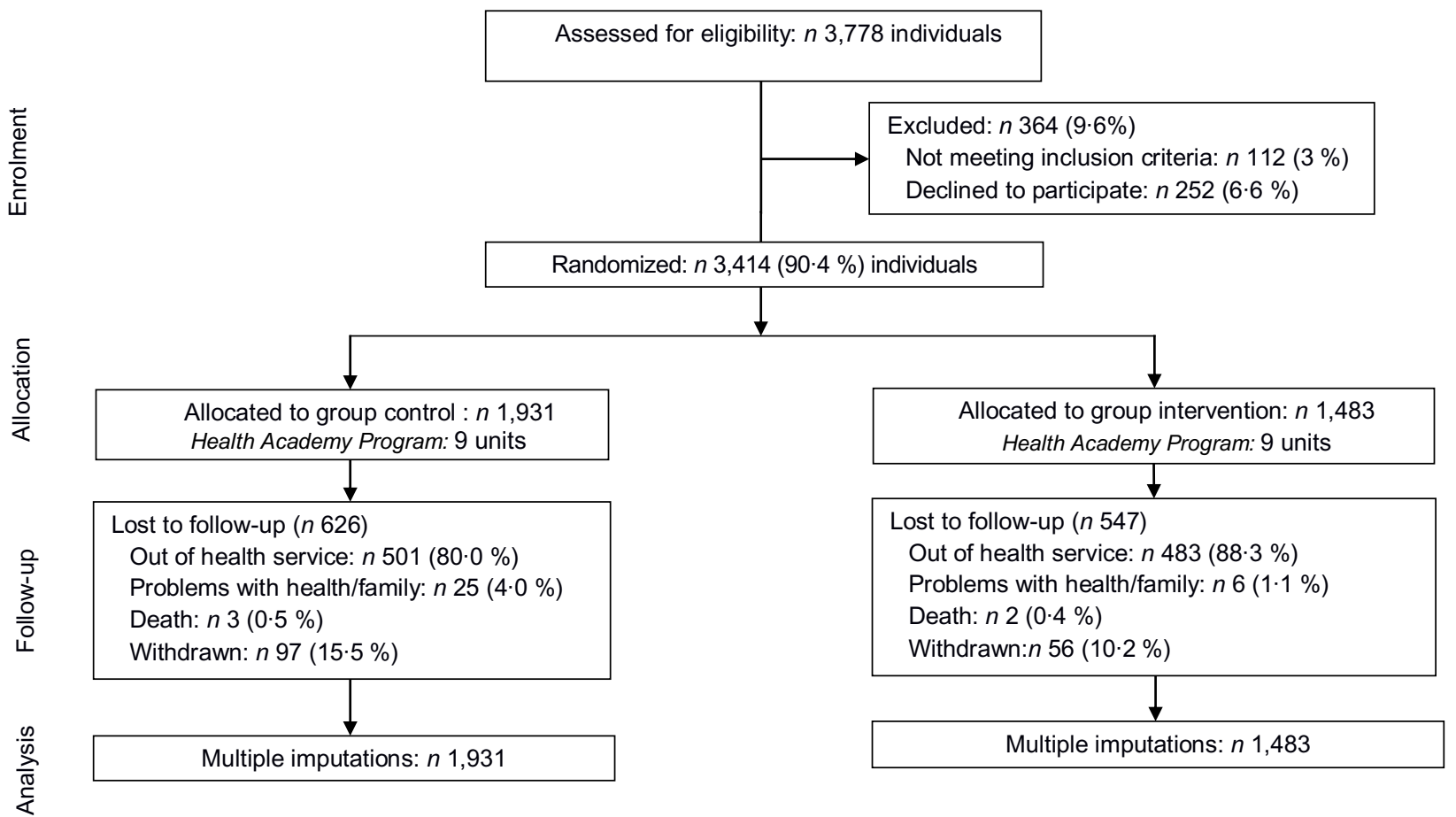

Fig. 1 Flowchart of the study design

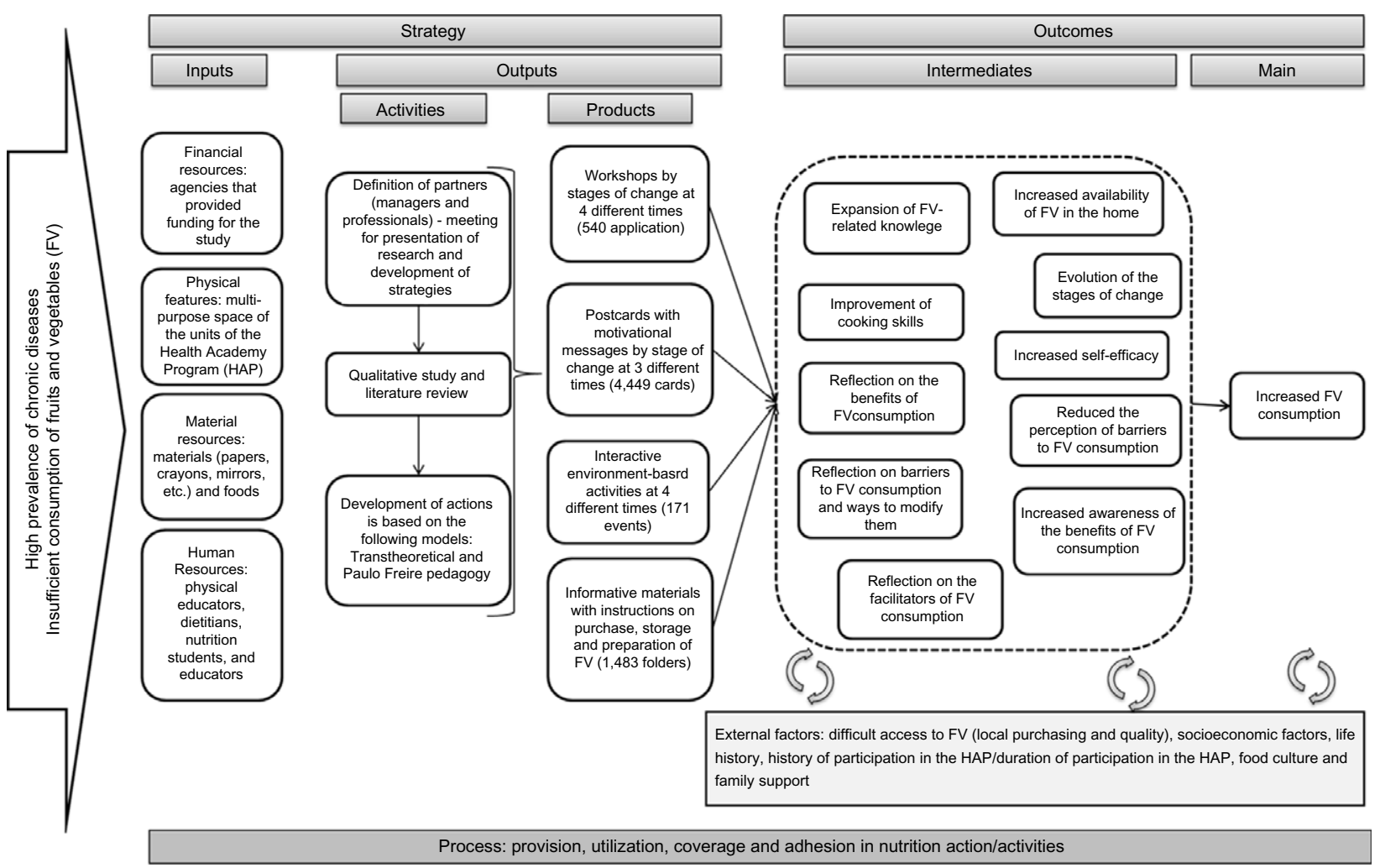

Fig. 2 Logic model for the development of nutritional intervention

educators and psychologists. In addition, a trained team of 3 nutritionists performed the educational activities ${ }^{(20)}$. We used a logic model to plan and evaluate the nutritional intervention (Fig. 2).
The intervention was based on the transtheoretical model $^{(14)}$ and Paulo Freire's problematising dialogic pedagogy ${ }^{(21)}$. This model facilitated the planning and implementation of actions according to individual characteristics 
including perception, readiness, attitude and motivation to undergo behavioural changes ${ }^{(14)}$. The model included 4 pillars: (1) stages of change; (2) processes of change; (3) self-efficacy and (4) decisional balance. The stages of change defined phases that involved action planning and development, and included, pre-contemplation: individuals did not intend on changing their behaviour in the foreseeable future; contemplation: individuals began to identify the need for change; preparation: individuals were ready to change their behaviour within $30 \mathrm{~d}$; action: individuals were capable of short, immediate changes for a period of up to 6 months; maintenance: an individuals' behaviour changed $>6$ months prior, requiring the prevention of relapse and consolidation of gains ${ }^{(14)}$.

The cognitive and behavioural processes of change underlined the understanding of how change occurs during the different stages. The educational activities focused on increasing awareness of behaviour and its consequences. Interventions were also aimed to increase an individuals' confidence in their ability to achieve the desired behaviour when faced with obstacles (self-efficacy) and to increase awareness of the benefits of a healthy diet while minimising the factors against change (decisional balance) ${ }^{(14)}$.

Problematising dialogic pedagogy, proposed by Paulo Freire, was chosen as a theory to guide the intervention development, to advance the transtheoretical model and advocate autonomy and empowerment. In this theory, education creates the possibility of liberation, which promotes conscientious attitudes and presumes a horizontal and dialogical relationship between participants, which is aimed at knowledge exchange instead of a relationship in which one is superior to the other ${ }^{(21)}$.

To define the subject matters on FV to be studied, a qualitative pilot study was conducted to examine social representations associated with $\mathrm{FV}$ intake ${ }^{(22)}$. This study identified the priority categories including food portions; nutritional information on FV and obstacles including cost, flavour, reduced family support, the time required to buy and prepare food and difficulties in shopping for good quality FV.

Four educational strategies were used: (1) group educational sessions, with up to 20 participants each; (2) motivational cards; (3) environment-based activities (e.g. movies and cooking competitions) and (4) informational materials. The cards and informational materials were delivered at the HAP centres with the assistance of healthcare professionals ${ }^{(20)}$.

The educational sessions and motivational cards varied across different stages of change with respect to FV intake. Each group was divided according to stages of change ${ }^{(20)}$. Thus, the participants were regrouped into: (1) pre-action (pre-contemplation and contemplation stages: individuals are not ready to change although they required action to shape their motivation); (2) decision (determination stage: individuals were ready to change their behaviour within 30 d) and (3) action (action and maintenance stages: individuals were capable of short, immediate changes, although the prevention of relapse and consolidation of gains was required ${ }^{(14,20)}$.

The intervention consisted of 4 group educational sessions monthly, 3 cards for each stage of change, 3 environment-based activities and 1 informational material; a total of 11 actions. To monitor attendance, we recorded the names of all participants who took part in each of the strategies. We sent workshop invitations to the participants by post and invited them through phone calls ${ }^{(20)}$.

\section{Outcome assessment: FV intake}

The outcome measure in this study was the change in FV intake (grams) during a follow-up of 7 months after the intervention (FV intake at 7 months - FV intake at baseline).

FV intake was assessed using questions (a brief questionnaire of $\mathrm{FV}$ intake evaluation) adapted from the National Risk Factor Surveillance System for Chronic Diseases $^{(23)}$ and validated in a previous study (correlation coefficients for the intake of fruits, vegetables and both FV were $0.44,0.34,0.37$, respectively; when compared with the $24-\mathrm{h}$ recall) ${ }^{(24)}$.

The participants were asked how often they consumed fruits (excluding juice) and vegetables (excluding potatoes and cassavas), their portion sizes (units for fruits and the numbers of tablespoons for vegetables) and preparation mode (for vegetables). The frequency of $\mathrm{FV}$ intake was reported in 6 categories: (1) never; (2) almost never; (3) 1-2 d/week; (4) 3-4 d/week; (5) 5-6 d/week or (6) every day ${ }^{(19,24)}$. For this, the QBrief-FV comprised 7 direct questions regarding the frequency of FV consumption. For fruit consumption, it was asked: 'How many days a week do you usually eat fruit?', followed by a question regarding the amount consumed (units, slices and size): 'On an ordinary day, how many servings of fruits do you eat' and 'On how many days of the week, do you usually eat at least one type of vegetable?' Next a question regarding quantities (tablespoons): 'On an ordinary day, how many spoons (soup) of vegetables do you eat?', in addition to the mode of consumption (raw or cooked) ${ }^{(19,24)}$.

Daily FV intake was estimated by multiplying the portion size by intake frequency (d/week) divided by $7 \mathrm{~d}$ (week). FV intake was calculated as the sum of the daily $\mathrm{FV}$ portions. FV intake (expressed in grams) was calculated by multiplying the portion of FV by $80 \mathrm{~g}^{(25,26)}$ :

Daily FV intake $($ grams $)=[($ portion intake frequency $) / 7] \times 80$.

The analyses were performed according to total FV intake $(\mathrm{g} / \mathrm{d})$ and separately for fruit $(\mathrm{g} / \mathrm{d})$ and vegetable $(\mathrm{g} / \mathrm{d})$ intake, considering that WHO recommends $400 \mathrm{~g}$ of FV daily $^{(1)}$, and the intake of nearly $200 \mathrm{~g}$ of each food group can be considered adequate, for example, $240 \mathrm{~g}$ of vegetables and $160 \mathrm{~g}$ of fruits daily ${ }^{(25,26)}$. Furthermore, it is possible that the population has different perceptions and behaviours related to FV intake ${ }^{(22)}$. 


\section{Secondary outcomes}

The secondary outcome measures included behavioural variables (i.e. stages of change, self-efficacy and decisional balance) and knowledge of FV crops (yes or no) ${ }^{(19)}$.

The stages of change were measured using an algorithm for the intake fruits and vegetables, separately. This algorithm assessed the readiness to change intake with the following response options: (1) pre-contemplation (not intending to increase FV intake in the next 6 months); (2) contemplation (intending to increase FV intake in the next 6 months); (3) preparation (intending to increase FV intake in the next $30 \mathrm{~d}$ ); (4) action (current adequate FV intake for $<6$ months) and (5) maintenance (current adequate $\mathrm{FV}$ intake for at least 6 months). For analysis, the participants were regrouped into 3 groups: pre-action, preparation and action $^{(14)}$.

Self-efficacy was used to assess a participant's confidence to change FV intake. Participants rated their confidence in 4 situations on a 5 -point Likert scale ( $1=$ not at all confident to $5=$ extremely confident). The 4 situations were: 'fruits and vegetables are easy to buy in my neighbourhood'; 'I can buy a variety of fruits and vegetables even when they are expensive'; 'I can consume the amount recommended of fruits and vegetables'; 'I have time to prepare/consume fruits and vegetables, even on days when I am in a hurry'(27). These were summed, with a higher score indicating a greater confidence.

The decisional balance measured a participant's perception of the benefits and barriers to FV intake. The question had 4 items regarding the benefits and 4 items regarding the barriers to $\mathrm{FV}$ intake ${ }^{(28)}$. Participants rated the importance of each item on a 5 -point Likert scale $(1=$ completely disagree to $5=$ completely agree). Responses were summed separately for each category, with a higher score indicating a higher perceived benefit or barrier ${ }^{(17)}$.

For knowledge on FV crops, participants were asked: 'Do you know what a FV crops is?' We include this data in the analysis, as one of the main obstacles, reported by a qualitative study, in increasing the consumption of $\mathrm{FV}$, was the high cost. In Brazil, when food is at the crop, they are generally cheaper, which may favour higher consumption of $\mathrm{FV}$, especially in vulnerable populations. Additionally, increasing self-efficacy, improving a participant's knowledge and ability to make plans and changing perceptions (benefits and barriers) could also aid in increasing the intake of $\mathrm{FV}$.

\section{Covariables}

We investigated the following demographic variables: sex, age, marital status (married, single, divorced and widowed), educational level ( $0-8$ years or $>8$ years), economic classes based on the Brazilian economic classification criteria (D/E-worst, C and A/B-best), occupation status (housewife, retired, unemployed and employed) and time of participation in HAP (years). The Brazil Economic
Classification Criterion estimates the purchasing power of urban people and families. The categorisation of a professional occupation was performed according to the profile of the program's users ${ }^{(19)}$. The demographic profiles were analysed based on Brazilian national studies ${ }^{(6)}$.

Additionally, we used anthropometric measurements (weight and BMI) ${ }^{(19)}$. Weight was measured with a calibrated digital scale, with an accuracy of $0.1 \mathrm{~kg}$. Height was measured using a stadiometer with a fixed vertical backboard and an adjustable headboard, with an accuracy of $0.1 \mathrm{~cm}$. The weight and height were measured with individuals wearing light clothing and barefoot, without props or objects on their head or in their pockets.

All data were collected in a face-to-face manner by nutrition students and nutritionists who were periodically trained by the researchers. A pilot study identified the adequacy of the research instruments for the population ${ }^{(19)}$.

\section{Statistical analyses}

All analyses were performed using Stata/sE, Version 13.1 (StataCorp., LP) and R software version 20. All $P$-values were 2-tailed and considered statistically significant if $<0.05$.

Incomplete data ( $n$ 815) on FV intake were imputed using multiple imputations by chained equations to avoid a loss of power. Differences in results with and without multiple imputations for those participants were minimal and non-significant. For the multiple imputation methods used in this study, it was assumed that the missing data occurred randomly (missing at random - MAR), that is, that the losses were not correlated with any variable and were not due to a selection bias. In this case, the estimates for the missing were obtained using only the observed data. The Multivariate Imputation by Chained Equations (MICE) package, from software R, was used.

To evaluate the effectiveness of the 7-month intervention, we analysed the main outcome, change in FV intake, separately and together, after 7 months of intervention (12 months from baseline), and secondary outcomes that included knowledge of FV crops, stages of change, self-efficacy and the decisional balance for FV intake.

Characteristics at baseline were presented as means and SDs. The differences between groups (CG $v$. IG) at baseline were assessed using $\chi^{2}$ and Student's $t$-tests for independent samples. The secondary outcomes were assessed at baseline and after 7 months (between-group differences) using $\chi^{2}$ and Student's $t$-tests for independent samples and within-group differences after 7 months (baseline $v$. follow-up) were determined using McNemar's and paired Student's tests.

The change in FV intake was treated as a continuous variable. The sample was divided into quartiles according to total FV, quartiles of vegetable and fruit intake $(\mathrm{g} / \mathrm{d})$ at baseline; the fourth quartile included the highest consumption.

A generalised estimating equation was used to examine the main outcome: FV and separately for fruits and 
vegetables intake. This analytic method was used to examine the associations of time-varying and time-constant independent variables with a time-varying dependent variable (e.g. FV intake). Assessments were conducted before the intervention and 7 months after (follow-up). Results were adjusted for baseline variables that were distributed differently among study participants and lost to follow-up, such as sex, age, education, time of participation in HAP, income/economic classes (based on the Brazilian economic classification criteria) and BMI.

\section{Results}

Of the 3414 participants included at baseline, $65.6 \%$ ( $n$ 2241) completed the trial: 1305 in the CG and 936 in the IG (Fig. 1). Losses to follow-up were more common among women, younger people, those with a higher education and those in the action stage. However, there were no differences in $\mathrm{FV}$ intake between retained participants and those lost to follow-up $(372.9 \mathrm{~g} / \mathrm{d} v .367 .6 \mathrm{~g} / \mathrm{d}$, $P=0 \cdot 21)$.

The participants had a mean age of 57.2 years $(95 \% \mathrm{CI}$ $56 \cdot 7,57 \cdot 5)$ and the majority was women (88.1\%) and had taken part in the HAP for approximately 2 years. The intervention and CGs had similar baseline characteristics, except for age and time of participation in the HAP (Table 1).

At baseline, the average daily FV intake was $370.4 \mathrm{~g} / \mathrm{d}$ (95\% CI 364.2, 376.6), fruits were $149.7 \mathrm{~g} / \mathrm{d}(95 \% \mathrm{CI}$ 145.6, 153.9) and vegetables $229.9 \mathrm{~g} / \mathrm{d}$ (95\% CI 226.8, 238.8) (Table 1). The participants who consumed $<80 \mathrm{~g} / \mathrm{d}$

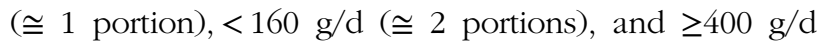
of $\mathrm{FV}$ ( $\geq 5$ portions) accounted for $3.1 \%, 10.3 \%$ and $42.9 \%$, respectively. The main fruits consumed were bananas, oranges and apples, and vegetables were tomatoes, lettuce and carrots ${ }^{(29)}$.

There was a loss of follow-up of $36.9 \%$ in the IG, and the main reasons reported for non-attendance included disengagement from the health service (60.5\%), employment or studying (13.6\%) and health or family problems (8.0\%). This study intervention offered 11 different actions to the IG, and approximately $90 \%$ of the participants took part in at least 5 types of educational activities resulting in a $60 \%$ adherence.

Regarding the secondary outcomes, participants in the IG showed progression in the stages of change, the percentage of those in the pre-action and decision stages decreased, whereas the percentage of those in the action stage increased $(P<0.001)$. In addition, we identified increased self-efficacy levels $(P<0.001)$ and improved knowledge of FV crops, and none of these changes were identified in the CG (Table 2).

The multivariate analysis of the evolution of $\mathrm{FV}$ intake, after 7 months of nutritional intervention (the main outcome), revealed that in the lowest quartile of FV intake, participants in the IG consumed more $\mathrm{FV}$ than those in the CG $(+23.4 \mathrm{~g} / \mathrm{d} ;(95 \%$ CI $6.7,40.0) ; P=0.01)$. However, those who had the highest consumption, and the highest quartile of FV at baseline, reduced their intake after the intervention, when the IG was compared with the CG $(-32 \cdot 1 \mathrm{~g} / \mathrm{d}$; $(95 \% \mathrm{CI}-60 \cdot 1,-4 \cdot 1) ; P=0 \cdot 03)$. However, the consumption was within the recommended daily amount of $400 \mathrm{~g}$. When we analysed the consumption of fruits and vegetables separately, we observed a reduction in the consumption of vegetables in the total sample and among those with high consumption (fourth quartile), but no change in the other quartiles of vegetable intake. For fruits, participants had the lower intake of fruits at baseline increased their intake after intervention $(+17.3 \mathrm{~g} / \mathrm{d}$; (95\% CI 5.1, 29.4); $P=0 \cdot 01$ ), when the IG was compared with the CG (Table 3).

\section{Discussion}

The nutritional intervention was effective in increasing total FV intake and fruits intake among individuals with a lower intake at baseline and in maintaining intake among those who reported consuming FV as recommended (400 g/d), mainly fruits. Additionally, participants in the IG showed improvements in the stage of change (action stage increased), self-efficacy, perceived benefits of FV intake and knowledge of $\mathrm{FV}$ crops, which may produce additional changes in FV intake.

The participants with lowered FV intakes in the IG had an average increase of $112 \mathrm{~g}$ (1.4 servings), which was higher than that reported in other studies. These results show that nutritional interventions can contribute to changes in FV intake. According to a systematic review of interventions, based on feeding behaviour theories, FV intake increased by 1.13 servings ( $\cong 90 \mathrm{~g} / \mathrm{d}$ ) among healthy adults, compared to only 0.97 servings ( $\cong 78 \mathrm{~g}$ ) among adults with a low-income and those from minority groups $^{(12)}$. A meta-analysis on behavioural interventions demonstrated that FV intake increased by $68.6 \mathrm{~g} / \mathrm{d}$ after 3 months of intervention and by $65.8 \mathrm{~g} / \mathrm{d}$ for interventions $>3$ months ${ }^{(30)}$. Another systematic review, on the effects of nutrition care provided by primary health professionals to adult patients, showed significant improvements in dietary behaviours, such as increased daily intake of foods including FV, high-fibre bread and fish. However, certain studies did not find any improvement in FV intake, and one study indicated a reduction in daily FV intake ${ }^{(31)}$.

Individuals appear to increase their FV intake depending on their intake at the baseline. People with a low intake increased their FV intake (quartile 1), adequate intake was maintained (quartiles 2 and 3) and those with high intake reduced their $\mathrm{FV}$ intake (quartile 4), although they still met the recommendation of $400 \mathrm{~g} / \mathrm{d}^{(1,26)}$. When analysed separately, we observed an increase in fruit consumption, especially among those with low consumption (quartiles 1 
Promoting FV intake in Brazilians

Table 1 Baseline characteristics of study participants

\begin{tabular}{|c|c|c|c|}
\hline Characteristics & Control group (n 1931) \% & Intervention group ( $n$ 1483) \% & $P$-value \\
\hline Sex & & & $0.07^{*}$ \\
\hline Female & $88 \cdot 9$ & $86 \cdot 9$ & \\
\hline Male & $11 \cdot 1$ & $13 \cdot 1$ & \\
\hline \multicolumn{4}{|l|}{ Age (years) } \\
\hline Mean & $57 \cdot 6$ & $56 \cdot 6$ & \multirow[t]{2}{*}{$0.02 \dagger$} \\
\hline $95 \% \mathrm{Cl}$ & $57 \cdot 1,58 \cdot 1$ & $56 \cdot 0,57 \cdot 3$ & \\
\hline \multicolumn{3}{|l|}{ Marital status } & \multirow[t]{5}{*}{$0 \cdot 71^{*}$} \\
\hline Married & 61.9 & $61 \cdot 1$ & \\
\hline Divorced & $7 \cdot 8$ & 8.9 & \\
\hline Single & $14 \cdot 1$ & $14 \cdot 2$ & \\
\hline Widowed & $16 \cdot 1$ & $15 \cdot 8$ & \\
\hline \multicolumn{3}{|l|}{ Education } & \multirow[t]{3}{*}{$0 \cdot 12^{*}$} \\
\hline $0-8$ years & $55 \cdot 5$ & $58 \cdot 2$ & \\
\hline$>8$ years & 44.5 & $41 \cdot 8$ & \\
\hline \multicolumn{3}{|l|}{ Economic classes $\ddagger$} & \multirow{4}{*}{$0.71^{*}$} \\
\hline A/B (\$694.20/family/month) & $29 \cdot 5$ & 29.5 & \\
\hline C (\$360.10/family/month) & 54.6 & $55 \cdot 6$ & \\
\hline D/E (\$218.47/family/month) & $15 \cdot 9$ & 14.9 & \\
\hline \multicolumn{3}{|l|}{ Occupation } & \multirow{5}{*}{$0.13^{*}$} \\
\hline Housewife & $28 \cdot 6$ & 28.7 & \\
\hline Retired & $36 \cdot 8$ & $36 \cdot 6$ & \\
\hline Unemployed & 1.5 & $2 \cdot 6$ & \\
\hline Employed & $33 \cdot 1$ & $32 \cdot 0$ & \\
\hline \multicolumn{4}{|l|}{ Time of participation in HAP (years) } \\
\hline Mean & 1.82 & 1.46 & \multirow[t]{2}{*}{$<0.01 \dagger$} \\
\hline $95 \% \mathrm{Cl}$ & $1.74,1.91$ & $1.39,1.52$ & \\
\hline \multicolumn{4}{|l|}{ Anthropometrics } \\
\hline Weight (kg) & & & \\
\hline Mean & 68.9 & 69.4 & \multirow{2}{*}{$0.31 \dagger$} \\
\hline $95 \% \mathrm{Cl}$ & $68 \cdot 3,69.5$ & $68 \cdot 7,70 \cdot 1$ & \\
\hline \multicolumn{4}{|l|}{ BMI $\left(\mathrm{kg} / \mathrm{m}^{2}\right)$} \\
\hline Mean & $27 \cdot 8$ & 27.9 & \multirow[t]{2}{*}{$0.73 \dagger$} \\
\hline $95 \% \mathrm{Cl}$ & $27 \cdot 6,28 \cdot 1$ & $27 \cdot 7,28 \cdot 1$ & \\
\hline \multicolumn{3}{|l|}{ Stage of change groups } & $0.13^{*}$ \\
\hline Pre-action & $16 \cdot 2$ & $18 \cdot 8$ & \\
\hline Decision & $36 \cdot 0$ & 34.7 & \\
\hline Action & $47 \cdot 8$ & $46 \cdot 5$ & \\
\hline Fruits $(\mathrm{g} / \mathrm{d})$ & & & \\
\hline Mean & 153.7 & $144 \cdot 6$ & $0.06 \dagger$ \\
\hline $95 \% \mathrm{Cl}$ & $148 \cdot 3,159 \cdot 1$ & $138 \cdot 1,151 \cdot 0$ & \\
\hline Vegetables $(\mathrm{g} / \mathrm{d})$ & & & \\
\hline Mean & $227 \cdot 8$ & $232 \cdot 8$ & $0.19 \dagger$ \\
\hline $95 \% \mathrm{Cl}$ & $223 \cdot 0,232 \cdot 6$ & $226 \cdot 8,238 \cdot 8$ & \\
\hline FV consumption (g/d) & & & \\
\hline Mean & $373 \cdot 1$ & 366.9 & $0.33 \dagger$ \\
\hline $95 \% \mathrm{Cl}$ & $365 \cdot 1,381 \cdot 1$ & $357 \cdot 1,376 \cdot 6$ & \\
\hline Quartiles of FV consumption (g/d) & & & $0 \cdot 22^{*}$ \\
\hline Q1 & & & \\
\hline Mean & $167 \cdot 2$ & $162 \cdot 0$ & \\
\hline $95 \% \mathrm{Cl}$ & $161 \cdot 8,172 \cdot 6$ & $156 \cdot 3,167 \cdot 8$ & \\
\hline Q2 & & & \\
\hline Mean & 309.9 & 308.9 & \\
\hline $95 \% \mathrm{Cl}$ & $306 \cdot 9,313 \cdot 0$ & $305 \cdot 3,312.5$ & \\
\hline Q3 & & & \\
\hline Mean & 429.7 & $425 \cdot 2$ & \\
\hline $95 \% \mathrm{Cl}$ & $426 \cdot 7,432 \cdot 7$ & $421.5,428.9$ & \\
\hline Q4 & & & \\
\hline Mean & 633.9 & $644 \cdot 3$ & \\
\hline $95 \% \mathrm{Cl}$ & $619 \cdot 6,648 \cdot 3$ & $627 \cdot 1,661 \cdot 4$ & \\
\hline
\end{tabular}

FV, fruit and vegetable; HAP, health academy programme; $Q$, quartile.

${ }^{*}$ Chi-squared test.

†Student's $t$-test.

¥Based on the Brazilian Economic Classification Criteria (estimate of family income per month).

Data are presented as percentages or means (95\% Cls). 


\section{Public Health Nutrition}

Table 2 Baseline values and changes after 7 months of follow-up within and between the control and intervention groups according to secondary outcomes including stages of change, self-efficacy and decisional balance

\begin{tabular}{|c|c|c|c|c|c|c|c|c|c|c|c|c|c|c|c|c|}
\hline \multirow[b]{3}{*}{ Variables } & \multicolumn{7}{|c|}{ Control group } & \multicolumn{7}{|c|}{ Intervention group } & \multirow{3}{*}{$\begin{array}{c}\begin{array}{c}\text { Between- } \\
\text { group: } \\
\text { baseline }\end{array} \\
P \text {-value }\end{array}$} & \multirow{3}{*}{$\begin{array}{c}\begin{array}{c}\text { Between-group: } \\
\text { after } 7 \text { months } \\
\text { of follow-up }\end{array} \\
P \text {-value }\end{array}$} \\
\hline & \multicolumn{2}{|c|}{ Baseline } & \multicolumn{2}{|c|}{ Follow-up } & \multicolumn{2}{|c|}{ Change } & \multirow[b]{2}{*}{$P$-value } & \multicolumn{2}{|c|}{ Baseline } & \multicolumn{2}{|c|}{ Follow-up } & \multicolumn{2}{|r|}{ Change } & \multirow[b]{2}{*}{$P$-value } & & \\
\hline & Mean & $95 \% \mathrm{Cl}$ & Mean & $95 \% \mathrm{Cl}$ & Mean & $95 \% \mathrm{Cl}$ & & Mean & $95 \% \mathrm{Cl}$ & Mean & $95 \% \mathrm{Cl}$ & Mean & $95 \% \mathrm{Cl}$ & & & \\
\hline \multicolumn{3}{|c|}{ Stage of change groups (\%) } & & & & & $0.46 \dagger$ & & & & & & & \multirow{4}{*}{$<0.001 \dagger$} & \multirow{4}{*}{$0.13 \S$} & \multirow{4}{*}{$<0.001 \S$} \\
\hline Pre-action & $16 \cdot 2$ & & $15 \cdot 4$ & & -0.7 & $-2 \cdot 7,1 \cdot 2$ & & $18 \cdot 8$ & & $12 \cdot 4$ & & $-6 \cdot 4$ & $-8 \cdot 6,-4 \cdot 2$ & & & \\
\hline Decision & $36 \cdot 0$ & & 27.5 & & -8.5 & $-11 \cdot 0,-6 \cdot 1$ & & 34.7 & & $18 \cdot 5$ & & $-16 \cdot 2$ & $-18 \cdot 9,-13 \cdot 4$ & & & \\
\hline Action & $47 \cdot 8$ & & $57 \cdot 1$ & & $9 \cdot 3$ & $6 \cdot 8,11 \cdot 7$ & & 46.5 & & 69.1 & & $22 \cdot 6$ & $19 \cdot 8,25 \cdot 3$ & & & \\
\hline Self-efficacy ${ }^{*}$ & 8.9 & $8 \cdot 7,9 \cdot 1$ & $8 \cdot 8$ & $8 \cdot 7,9 \cdot 0$ & -0.02 & $-0.2,0.1$ & $0.62 \ddagger$ & $8 \cdot 6$ & $8 \cdot 5,8 \cdot 8$ & $9 \cdot 1$ & $8 \cdot 9,9.3$ & 0.5 & $0.3,0.7$ & $<0.001 \ddagger$ & $0.03 \|$ & $0.01 \|$ \\
\hline \multicolumn{17}{|c|}{ Decisional balance } \\
\hline Benefits & $12 \cdot 6$ & $12 \cdot 5,12 \cdot 7$ & $12 \cdot 6$ & $12 \cdot 5,12 \cdot 7$ & 0.01 & $-0.1,0.1$ & $0.76 \ddagger$ & $12 \cdot 4$ & $12 \cdot 3,12 \cdot 5$ & $12 \cdot 5$ & $12 \cdot 3,12 \cdot 6$ & 0.05 & $-0.1,0.2$ & $0.52 \ddagger$ & $0.01 \|$ & $0.03 \|$ \\
\hline Barriers & 6.1 & $5 \cdot 9,6 \cdot 2$ & $6 \cdot 1$ & $5 \cdot 9,6 \cdot 2$ & -0.0 & $-0.2,0.1$ & $0.97 \ddagger$ & $6 \cdot 2$ & $6 \cdot 1,6 \cdot 3$ & 6.0 & $5 \cdot 9,6 \cdot 2$ & -0.2 & $-0.3,0.0$ & $0.06 \ddagger$ & 0.41 & $0.37 \|$ \\
\hline FV crops (\%) & 78.2 & & $76 \cdot 4$ & & -1.7 & $-3 \cdot 9,0.4$ & $0.12 \dagger$ & 70.9 & & $77 \cdot 2$ & & 6.3 & $3 \cdot 6,9 \cdot 1$ & $<0.001 \dagger$ & $<0.001 \S$ & $0.59 \S$ \\
\hline
\end{tabular}

* Self-efficacy and decisional balance items were scored on a 5-point scale from 1 to 5 (maximum score of 20). For benefits, higher scores indicate greater perceived benefits; lower scores indicate smaller perceived barriers. †McNemar test.

†Paired Student test

§Chi-squared test.

Data are presented as percentages or means $(95 \% \mathrm{Cls})$. 


\section{Public Health Nutrition}

Table 3 Change in daily fruit and vegetable consumption according to an intervention

\begin{tabular}{|c|c|c|c|c|c|c|c|c|c|c|c|c|c|c|c|c|c|}
\hline \multirow[b]{3}{*}{$\mathrm{FV}$ consumption (g/d) } & \multicolumn{6}{|c|}{ Control } & \multicolumn{6}{|c|}{ Intervention } & \multirow[b]{3}{*}{$P$-value } & & & \multirow{2}{*}{\multicolumn{2}{|c|}{$\begin{array}{l}\text { Between-group } \\
\text { difference }{ }^{*}, \dagger\end{array}$}} \\
\hline & \multicolumn{2}{|c|}{ Baseline $(\mathrm{g} / \mathrm{d})$} & \multicolumn{2}{|c|}{ Follow-up (g/d) } & \multicolumn{2}{|c|}{ Mean differences } & \multicolumn{2}{|c|}{ Baseline (g/d) } & \multicolumn{2}{|c|}{ Follow-up (g/d) } & \multicolumn{2}{|c|}{ Mean differences } & & \multicolumn{2}{|c|}{$\begin{array}{l}\text { Between-group } \\
\text { difference }^{*}\end{array}$} & & \\
\hline & Mean & $95 \% \mathrm{Cl}$ & Mean & $95 \% \mathrm{Cl}$ & Mean & $95 \% \mathrm{Cl}$ & Mean & $95 \% \mathrm{Cl}$ & Mean & $95 \% \mathrm{Cl}$ & Mean & $95 \% \mathrm{Cl}$ & & Mean & $95 \% \mathrm{Cl}$ & Mean & $95 \% \mathrm{Cl}$ \\
\hline Fruits & 153.7 & $148 \cdot 3,159 \cdot 1$ & 158.4 & $153 \cdot 2,163 \cdot 6$ & 4.7 & $-0 \cdot 8,10 \cdot 2$ & 144.6 & $138 \cdot 1,151 \cdot 0$ & $163 \cdot 1$ & $157 \cdot 1,169 \cdot 0$ & 18.5 & $11 \cdot 5,25 \cdot 5$ & 13.8 & $4 \cdot 9,22 \cdot 7$ & 13.8 & $4 \cdot 9,22 \cdot 7$ & $0.002 \ddagger$ \\
\hline Q1 & & & & 78.1 & 74.4 & 66.3, & 12.0 & 10.5 & $103 \cdot 1$ & $93.8,112.5$ & 91.1 & $81 \cdot 8,100 \cdot 4$ & & $4.3,28.9$ & 16 & $4.4,29.0$ & $0.01 \neq$ \\
\hline Q2 & 115.6 & $112 \cdot 7,118.5$ & $\begin{array}{r}00.5 \\
143.1\end{array}$ & $135.4,150.8$ & 27.5 & $\begin{array}{l}19 \cdot 8,35 \cdot 2 \\
19 \cdot 8\end{array}$ & 115.3 & 112.0, $118 \cdot 6$ & 160.0 & $150.8,169 \cdot 3$ & 44.8 & $\begin{array}{l}0.0,10 \cdot 4 \\
35 \cdot 3,54 \cdot 2\end{array}$ & $\begin{array}{l}17.0 \\
17.2\end{array}$ & $\begin{array}{l}4.3,20.9 \\
5.1,29.5\end{array}$ & $\begin{array}{l}10.7 \\
17.3\end{array}$ & $5.1,29.4$ & $\begin{array}{l}0.01 \neq \\
0.01 \neq\end{array}$ \\
\hline Q3 & 232.8 & $231 \cdot 3,234 \cdot 3$ & 207.5 & $198 \cdot 0,217.0$ & $-25 \cdot 3$ & $-34.7,-15.9$ & 233.6 & $231 \cdot 9,235 \cdot 4$ & 208.9 & $197 \cdot 7,220 \cdot 0$ & -24.8 & $-35 \cdot 9,-13 \cdot 6$ & 0.6 & $-14 \cdot 0,15 \cdot 1$ & 0.6 & $-14 \cdot 0,15 \cdot 1$ & \\
\hline Q4 & 371.0 & $358 \cdot 0,383.9$ & 237.0 & $222 \cdot 1,251 \cdot 9$ & -134.0 & $-151 \cdot 3,-116 \cdot 6$ & 378.4 & $358.4,398.4$ & $224 \cdot 2$ & $204 \cdot 7,243 \cdot 7$ & $-154 \cdot 2$ & $-181 \cdot 1,-127 \cdot 3$ & $-20 \cdot 2$ & $-52 \cdot 0,11 \cdot 5$ & $-20 \cdot 2$ & $-52 \cdot 0,11.5$ & 0.2 \\
\hline Vegetables & 227.8 & $223 \cdot 0,232 \cdot 6$ & 212.7 & 208.4, $217 \cdot 1$ & $-15 \cdot 1$ & $-20 \cdot 6,-9 \cdot 6$ & 232.8 & $226 \cdot 8,238 \cdot 8$ & $207 \cdot 3$ & $202 \cdot 2,212 \cdot 4$ & -25.5 & $-32 \cdot 2,-18 \cdot 8$ & -10.5 & $-19 \cdot 1,-1 \cdot 8$ & -10.4 & $-19 \cdot 1,-1 \cdot 8$ & $0.02 \ddagger$ \\
\hline Q1 & 132.9 & $130 \cdot 6,135 \cdot 3$ & 182.4 & $176 \cdot 5,188 \cdot 2$ & 49.4 & $43,4,55 \cdot 3$ & 131.7 & $128 \cdot 9,134.4$ & $179 \cdot 3$ & $171 \cdot 8,186 \cdot 8$ & 47.6 & $40 \cdot 1,55 \cdot 1$ & -1.8 & $-11 \cdot 3,7.8$ & -1.8 & $-11 \cdot 3,7 \cdot 8$ & 0.72 \\
\hline Q2 & 193.4 & $192 \cdot 4,194.4$ & $205 \cdot 1$ & $195 \cdot 5,214 \cdot 7$ & 11.6 & $2 \cdot 1,21 \cdot 2$ & 192.5 & $191 \cdot 3,193.7$ & 202.7 & $191 \cdot 4,214 \cdot 0$ & 10.2 & $-1 \cdot 21,21 \cdot 6$ & -1.4 & $-16 \cdot 2,13 \cdot 4$ & -1.4 & $-16 \cdot 3,13 \cdot 4$ & 0.85 \\
\hline Q3 & $247 \cdot 2$ & $245 \cdot 6,248.9$ & $225 \cdot 2$ & $217 \cdot 2,233 \cdot 1$ & $-22 \cdot 1$ & $-30 \cdot 0,-14 \cdot 1$ & 248.1 & $246 \cdot 2,250 \cdot 1$ & 217.0 & $206 \cdot 9,227 \cdot 1$ & $-31 \cdot 1$ & $-41 \cdot 2,-20 \cdot 9$ & -9.0 & $-21 \cdot 9,3 \cdot 8$ & -9.0 & $-21 \cdot 9,3.8$ & 0.19 \\
\hline Q4 & 393.4 & $382 \cdot 8,403 \cdot 9$ & 253.8 & $241 \cdot 8,265 \cdot 8$ & -139.5 & $-154 \cdot 6,-124 \cdot 4$ & 404.6 & $392 \cdot 0,417 \cdot 1$ & $243 \cdot 3$ & $231 \cdot 4,255 \cdot 2$ & $-161 \cdot 3$ & $-176 \cdot 4,-146 \cdot 1$ & -21.7 & $-43 \cdot 0,-0.4$ & $-21 \cdot 7$ & $-43.0,-0.4$ & $0.05 \ddagger$ \\
\hline Total FV & 373.1 & $365 \cdot 1,381 \cdot 1$ & 362.2 & $333 \cdot 3,365 \cdot 1$ & -10.9 & $-18 \cdot 3,-3 \cdot 5$ & 366.9 & $357 \cdot 1,376 \cdot 6$ & 361.7 & $354 \cdot 1,369 \cdot 3$ & $-5 \cdot 2$ & $-14.4,4.0$ & 5.7 & $-6 \cdot 1,17 \cdot 5$ & 5.6 & $-6 \cdot 2,17 \cdot 5$ & 0.35 \\
\hline Q1 & $167 \cdot 2$ & $161 \cdot 8,172 \cdot 6$ & 255.9 & $244 \cdot 9,266 \cdot 8$ & 88.7 & $77.6,99.7$ & 162.0 & $156 \cdot 2,167 \cdot 8$ & 274.1 & $261 \cdot 6,286 \cdot 5$ & 112.1 & $99.6,167.8$ & $23 \cdot 4$ & $6 \cdot 7,40.0$ & 23.4 & $6 \cdot 7,40.0$ & $0.01 \ddagger$ \\
\hline Q2 & 309.9 & $306.9,313.0$ & 336.0 & $324 \cdot 9,347 \cdot 1$ & $26 \cdot 1$ & $15 \cdot 1,37 \cdot 1$ & 308.9 & $305 \cdot 3,312.5$ & 346.9 & $333 \cdot 6,360 \cdot 2$ & 37.9 & $24 \cdot 5,51 \cdot 4$ & 11.8 & $-5 \cdot 9,29 \cdot 2$ & 11.8 & $-5 \cdot 4,29 \cdot 2$ & 0.18 \\
\hline Q3 & 429.7 & $426 \cdot 7,432 \cdot 7$ & $400 \cdot 2$ & $388.9,411.5$ & -29.5 & $-40 \cdot 7,-18 \cdot 3$ & 425.2 & $421.5,428.9$ & 398.6 & $385 \cdot 2,411 \cdot 9$ & -26.7 & $-39 \cdot 9,-13 \cdot 4$ & 2.8 & $-14.5,20 \cdot 1$ & 2.8 & $-14.5,20 \cdot 1$ & 0.75 \\
\hline Q4 & 633.9 & $619 \cdot 6,648 \cdot 3$ & 476.0 & $460 \cdot 3,491 \cdot 7$ & -157.9 & $-176 \cdot 9,-138.9$ & 644.3 & $627.1,661.4$ & 454.4 & $437 \cdot 9,470 \cdot 8$ & -189.9 & $-210 \cdot 7,-169 \cdot 1$ & -31.9 & $-60 \cdot 0,-3.9$ & -32.1 & $-60 \cdot 1,-4.1$ & $0.03 \ddagger$ \\
\hline
\end{tabular}

$\mathrm{FV}$, fruit and vegetables; $\mathrm{Q}$, quartile.

${ }^{*}$ Coefficient $(\beta)(95 \% \mathrm{Cl})$.

†Adjusted for sex, age, education (years), attending the programme (years), Brazilian economic classification and BMI.

$\ddagger$ Statistically significant $>005$

Data are presented as means $(95 \% \mathrm{Cls})$ 
and 2) and a reduction in vegetable consumption among those with higher consumption (quartile 4), following the same trend when analysing the consumption of fruits and vegetables together. These results are consistent with WHO recommendations, and it appears that the intervention achieved the purpose of increasing knowledge, empowering participants and promoting conscientious attitudes ${ }^{(21)}$. The participants were able to identify a need for change (intake lower or higher than the recommendation), especially those with an intake below the recommendation.

An increase of one FV serving $(80 \mathrm{~g} / \mathrm{d})$ can reduce the risk of all-cause mortality by $5 \%$ and the risk of CVD mortality by $4 \%{ }^{(2)}$; the intake of even 3 servings per day $(375 \mathrm{~g} / \mathrm{d})$ has health benefits ${ }^{(32)}$. A systematic review of meta-analyses showed that protective associations significantly increased the intakes of $200 \mathrm{~g} / \mathrm{d}$ but slightly increased or decreased the intakes of $>300 \mathrm{~g} / \mathrm{d}^{(33)}$.

It is necessary to emphasise that FV intake was high at baseline in both the IG and CG. Two-fifths of the participants in the IG reached the recommended daily intake of $400 \mathrm{~g}$, and the average fruit intake was higher than the Brazilian and international data ${ }^{(4-6)}$. A study that included 143305 adults from 18 countries in 5 continents across income levels showed that the mean FV intake was $2 \cdot 14$ servings $(\cong 171 \mathrm{~g})$ in low-income countries $^{(7)}$. In addition to high fruit consumption, the intake in the CG also increased in our study compared with Brazilian data (baseline $)^{(23)}$. A possible explanation is that participating in a health service can promote healthy eating, including FV intake, and the nutritional intervention enhances the adoption of healthy eating. This results in an adequate FV intake among the majority of HAP participants living in poor communities and raises the hypothesis that the primary care service model used in HAP may be a way to overcome the global challenge of increasing FV intake.

In addition, improvements in self-efficacy, knowledge of FV crops, stages of change and perceived benefits of FV intake may support additional changes in FV intake among the participants over a long-term period. This study presents the methodology of an innovative intervention for the promotion of FV intake among adults, based on an individuals' perceptions of their consumption habits. Evidence suggests that stages of change, self-efficacy, social support and knowledge are predictors of FV intake ${ }^{(14,34,35)}$. Studies have shown that individuals in action and maintenance stages are more likely to follow diets than individuals in the pre-contemplation, contemplation and preparation stages; moreover, their FV intake is likely to be higher $^{(14,35,36)}$. The increase in self-efficacy and perceived benefits can also be reflected in the progression of the stages of change and the increased number of people in the action group ${ }^{(36)}$. Nutritional interventions should include education on the health benefits of healthy food and actions that increase self-efficacy, improve a participant's ability to make plans and change behaviours to increase FV intake ${ }^{(35)}$.
FV intake appears to be higher among individuals with a higher self-efficacy and a better perception of the food environment ${ }^{(37)}$. The consumer's food environment, in turn, could affect FV intake as the access to commercial establishments appeared to be important for the quantitative intake ${ }^{(29)}$. To reach the recommended intake, as verified here, we believe that the educational activities should be developed and sustained based on scientific evidence. Furthermore, these activities should cover information regarding improved accessibility, availability and quality of FV.

This intervention achieved positive outcomes because of the planning of inputs, the logic model for the development of the nutritional intervention, activities and expected results, as well as the involvement of healthcare professionals ${ }^{(38,39)}$. Additionally, the primary care services are strategic for the development of nutritional interventions because they can provide additional social support among individuals by improving their knowledge. Therefore, a nutritional intervention can contribute to increasing self-efficacy and reducing perceived barriers according to the intention and readiness to change food intake habits.

One issue that may have prevented us from achieving better results with the intervention was the high percentage ( $42.9 \%)$ of participants reporting adequate FV intake at baseline. This may be partly because the study was conducted with participants in the HAP, a programme that aims to promote healthy lifestyles. However, previous studies on these services showed that service users with inadequate FV intake accounted for $60-75 \%{ }^{(19,29)}$; these low percentages were among the motivations for this work. But, these studies only evaluated participants when they started participating in the HAP; and our study covered all users, regardless of the time of participation in the HAP, which possibly helped to show how much the HAP can contribute to healthy eating. In the general population, FV intake may be lower, and the change after an intervention could be greater. Given the demand for additional and improved information on the effectiveness of actions under real-life conditions and the potential to contribute to greater sustainability of results, this study highlights the need to conduct further studies, mainly in the health services.

The results may have been affected by the differences between the 2 groups at baseline and by follow-up losses. The adjustments in the analysis and multiple imputations were used to minimise these possible problems. Segmental losses occurred mainly among women, young people and people with a higher education. However, all analyses were adjusted accordingly to minimise the impact on the results. This was likely because of the opening hours of service in the morning, which may have hindered the adherence among economically active individuals $^{(19,20,39)}$, but the adherence was higher than national and international values namely, $22.7 \%$ to 
$56.0 \%{ }^{(36)}$. In addition, we implemented all the possible ways to ensure a high retention rate of our participants such as maintaining contact through phone calls. In addition, we evaluated differences in baseline characteristics of those participants lost during follow-up versus those retained in the study. Differences in FV intake between lost and retained participants were minimal and NS (CG $P$-value $=0.45$ and IG $P$-value $=0.32$ ). To reduce the uncertainty of variation between pre- and postintervention, we adjusted for possible confounding factors (sex, age, education, participation in the HAP, and $\mathrm{BMI})$; and longitudinal analysis was performed to determine the effects of the intervention on controlling for similarities among individuals and $\mathrm{FV}$ intake.

The difficulty in obtaining reliable measures of food intake has been identified as a limiting factor in the literature. Inherent to our methodology, there is the potential for some degree of misclassification of $\mathrm{FV}$ intake. It cannot be excluded that self-reports of FV intake are susceptible to substantial social approval bias. As previously indicated, a greater subject-specific bias existed in self-reported FV intake in the CG compared to the treatment group ${ }^{(40)}$. In summary, self-reported information could have led to some degree of overestimation or underestimation of the effectiveness of the intervention. However, QBrief-FV has been previously validated, and we used the same questionnaire at baseline and follow-up that was provided by trained staff, and professionals involved in the intervention did not participate in the data collection at the intervention Primary Health Care services. We emphasise that all data were collected by nutrition students and nutritionists trained periodically. Data collection procedures were standardised, and protocols were used to minimisse errors and biases. This contributes to the increased reliability of our data.

Caution is required regarding the external validity of the data. HAP participants are regular users of the service aimed at health promotion, with a focus on physical activity; therefore, they may be more health conscious and have a higher average FV intake than the general population. Caution is required when extrapolating our results to the general population because the participants attend a service aimed at promoting health and focusing on the practice of physical exercise, which renders the participants more aware of their health. However, we believed that the results from this study could be extrapolated to other populations of Primary Health Care users. We, therefore suggest that the intervention be tested in other population groups in order to verify its effectiveness.

It should be noted that all actions (group educational sessions, motivational cards, environment-based activities and informational materials) were designed to be reapplied in primary care and all materials prepared by the research was made available for primary care with instructions on how to apply. Other strengths of this study include the design, the large sample size and the use of validated methods to assess consumption of FV, all data were collected in a face-to-face manner by nutrition students and nutritionists who were periodically trained. A pilot test identified the adequacy of the research instruments for the population studied. Adherence to the intervention was similar or higher than other studies, and the methodology of the intervention appeared to contribute to adherence ${ }^{(39)}$. The intervention was effective among people who had a low FV consumption, mainly fruits, but the consumption, within the recommended guideline $(400 \mathrm{~g} / \mathrm{d})$, was maintained among the other participants. Thus, we hypothesise that the nutritional intervention should be carried out according to the demands and needs of the population.

In conclusion, this was a randomised trial for $\mathrm{FV}$ promotion held by the health service system with a lowincome population. Our results suggest that the nutritional intervention, based on the perception of intake and group activities, was effective in increasing FV intake among individuals with low total $\mathrm{FV}$ intake, mainly fruits, and maintaining FV intake among those with sufficient FV intake. The increase in knowledge, self-efficacy and perception of benefits corroborates that a nutritional intervention could be considered a useful tool in promoting $\mathrm{FV}$ intake. However, to confirm the study's results, we suggest that future studies should be conducted over a longer period in different contexts, with a focus on analysing the maintenance of these changes.

\section{Acknowledgements}

Acknowledgements: We thank participants of the Project for their continued cooperation and participation. We thank all the members of the HAP for technical, and material support. R.D. Mendonça would also like to thank Capes Foundation, Ministry of Education of Brazil for the scholarship to continue his training at the University of Navarra, Spain. Financial support: This work was supported by the Fundação de Amparo à Pesquisa de Minas Gerais (grant number 21618/2013, APQ-03376-12 e PPM-00254-15); Conselho Nacional de Desenvolvimento Científico e Tecnológico (grant number 476686/2013-0 and a research productivity scholarship for A.C.S.L.); and Coordenação de Aperfeiçoamento de Pessoal de Nivel Superior, Brasil (CAPES) (Finance Code 001). The funders had no role in the design, analysis or writing of this article. Conflict of interest: There are no conflicts of interest. Authorship: R.D.M. and A.C.S.L. analysed the data and drafted the manuscript. A.C.S.L. obtained funding and designed the study. R.D.M., M.F.G.B., S.A.M., M.A.M., M.B.R. and A.C.S.L. helped to design the study and participated in data interpretation. All authors participated in the critical revision of the manuscript for important intellectual content and approved the final version to be 
submitted for publication. Ethics of human subject participation: This study was conducted according to the guidelines laid down in the Declaration of Helsinki and all procedures involving research study participants were approved by the the Universidade Federal de Minas Gerais Research Ethics Committees (No. 0537.0.0203.000-11 and No. 0537.0.0203.410-11A) and recorded in the Brazilian Registry of Clinical Trials (RBR-9h7ckx). All participants were informed about the study objectives and methods through a letter. Written informed consent was obtained from all subjects/patients.

\section{References}

1. World Health Organization (2011) Global Status Report on Non-communicable Diseases 2010. https://www.who.int/ $\mathrm{nmh} /$ publications/ncd_report2010/en/ (accessed July 2019).

2. Aune D, Giovannucci E, Boffetta P et al. (2017) Fruit and vegetable intake and the risk of cardiovascular disease, total cancer and all-cause mortality: a systematic review and dose-response meta-analysis of prospective studies. Int $J$ Epidemiol 46, 1029-1056.

3. Wang X, Ouyang Y, Liu J et al. (2014) Fruit and vegetable intake and mortality from all causes, cardiovascular disease, and cancer: systematic review and dose-response metaanalysis of prospective cohort studies. BMJ 349, g4490.

4. OECD/European Union (2016) Health at a Glance: Europe 2016: State of Health in the EU Cycle. Paris: OECD Publishing. doi: 10.1787/9789264265592-en.

5. Centres for Disease Control and Prevention (2018) State Indicator Report on Fruits and Vegetables, 2018. https:// www.cdc.gov/nutrition/downloads/fruits-vegetables/2018/ 2018-fruit-vegetable-report-508.pdf (accessed January 2018).

6. Instituto Brasileiro de Geografia e Estatística (2014) National Health Survey 2013. Rio de Janeiro: Instituto Brasileiro de Geografia e Estatística. https://biblioteca.ibge.gov.br/ visualizacao/livros/liv94074.pdf (accessed April 2021).

7. Miller V, Yusuf S, Chow CK et al. (2016) Availability, affordability, and intake of fruits and vegetables in 18 countries across income levels: findings from the prospective urban rural epidemiology (PURE) study. Lancet Glob Health 4, e695-e703.

8. Keller J, Motter S, Motter M et al. (2018) Augmenting fruit and vegetable intake by an online intervention: psychological mechanisms. Appetite 120, 348-355.

9. Wagner MG, Rhee Y, Hert-Honrath K et al. (2016) Nutrition education effective in increasing fruit and vegetable intake among overweight and obese adults. Appetite 100, 94-101.

10. Barnidge EK, Baker EA, Schootman M et al. (2015) The effect of education plus access on perceived fruit and vegetable intake in a rural African American community intervention. Health Educ Res 30, 773-785.

11. Pomerleau J, Lock K, Knai C et al. (2005) Interventions designed to increase adult fruit and vegetable intake can be effective: a systematic review of the literature. $J$ Nutr 135, 2486-2495.

12. Thomson CA \& Ravia J (2011) A systematic review of behavioural interventions to promote intake of fruit and vegetables. J Am Diet Assoc 111, 1523-1535.

13. Cervato-Mancuso AM, Vincha KRR \& Santiago DA (2016) Food and Nutrition Education intervention practice: reflection and possible strengthening. Physis 26, 225-249.

14. Krebs P, Norcross JC, Nicholson JM et al. (2018) Stages of change and psychotherapy outcomes: a review and metaanalysis. J Clin Psychol 74, 1964-1979.
15. Canella DS, Silva ACF \& Jaime PC (2013) Scientific output on nutrition in the scope of Primary Health Care in Brazil: a review of the literature. Ciên Saúde Colet 18, 297-308.

16. Jaime PC, Delmuè DCC, Campello TS et al. (2018) A look at the food and nutrition agenda over thirty years of the Unified Health System. Ciên Saúde Colet 23, 1829-1836.

17. Instituto Brasileiro De Geografia e Estatística (2013) Demographic Census. https://www.ibge.gov.br/ (accessed February 2014).

18. Ministério da Saúde (2013) Portaria $n^{\circ} 2.681$, de 7 de Novembro de 2013: Redefine o Programa Academia da Saúde no Âmbito do Sistema Único de Saúde (SUS). http://bvsms.saude.gov.br/bvs/saudelegis/gm/2013/prt2681_ 07_11_2013.html (accessed May 2018).

19. Menezes MC, Costa BVL, Ferreira NL et al. (2017) Methodological course of a community-controlled trial in a health care services: a translational epidemiological research on nutrition. Demetra 12, 1203-1222.

20. Menezes MC, Mendonça RD, Ferreira NL et al. (2018) Promoting fruit and vegetable intake: methodological proto$\mathrm{col}$ of a randomised controlled community trial. Contemp Clin Trials Commun 10, 131-136.

21. Freire P (2013) Pedagogy of the Oppressed. New York: Continuum.

22. Figueira TR, Lopes ACS \& Modena CM (2014) Assessing fruit and vegetable intake among families of users of the academy of health programme (PAS). RBPS 27, 518-526.

23. Ministério da Saúde (2015) Vigitel Brazil 2014: Protection and Risk Factors for Chronic Diseases by Telephone Inquiry. Brasília: Ministério da Saúde.

24. Lopes MS, Santos LC, Lopes ACS et al. (2017) Comparison between two assessment tools for fruit and vegetable intake relative to the 24-h recall. Nutrition 38, 34-40.

25. Agudo A (2005) Measuring Intake of Fruit and Vegetables. Joint FAO/WHO Workshop on Fruit and Vegetables for Health, 1-3 September 2004. Kobe: WHO.

26. World Health Organization (2004) Fruit and Vegetables for Health. Joint FAO/WHO Workshop, 1-3 September 2004. Kobe: WHO.

27. Mainvil LA, Lawson R, Horwath CC et al. (2009) Validated scales to assess adult self-efficacy to eat fruits and vegetables. Am J Health Promot 23, 210-217.

28. Mainvil LA, Lawson R, Horwath CC et al. (2010) Validated scales to assess decisional balance to eat fruits and vegetables. Appetite 55, 454-465.

29. Mendonça RD, Lopes MS, Freitas PP et al. (2019) Monotony in the intake of fruits and vegetables and food environment characteristics. Rev Saude Publica 53, 63.

30. Ashton LM, Sharkey T, Whatnall MC et al. (2019) Effectiveness of interventions and behavior change techniques for improving dietary intake in young adults: a systematic review and meta-analysis of RCTs. Nutrients 11, 825 .

31. Ball L, Leveritt M, Cass S et al. (2015) Effect of nutrition care provided by primary health professionals on adults' dietary behaviours: a systematic review. Fam Pract 32, 605-617.

32. Miller V, Mente A, Dehghan M et al. (2017) Fruit, vegetable, and legume intake, and cardiovascular disease and deaths in 18 countries (PURE): a prospective cohort study. Lancet 390, 2037-2049.

33. Yip CSC, Chan W \& Fielding R (2019) The associations of fruit and vegetable intakes with burden of diseases: a systematic review of meta-analyses. J Acad Nutr Diet 119, 464-481.

34. Shaikh AR, Yaroch AL, Nebeling L et al. (2008) Psychosocial predictors of fruit and vegetable intake in adults. A review of the literature. Am J Prev Med 34, 535-543.

35. Henry H, Reimer K, Smith C et al. (2006) Associations of decisional balance, processes of change, and self-efficacy with 
stages of change for increased fruit and vegetable intake among low-income, African-American mothers. J Am Diet Assoc 106, 841-849.

36. Norcross JC, Krebs PM \& Prochaska JO (2011) Stages of change. J Clin Psychol 67, 143-154.

37. Menezes MC, Diez Roux AV \& Souza Lopes AC (2018) Fruit and vegetable intake: influence of perceived food environment and self-efficacy. Appetite 127, 249-256.

38. Contandriopoulos D, Brousselle A \& Kêdoté NM (2008) Evaluating interventions aimed at promoting information utilisation in organizations and systems. Healthc Policy $\mathbf{4}$, 89-107.

39. Mendonça RD, Guimarães LMF, Mingoti SA et al. (2019) Barriers to and facilitators for adherence to nutritional intervention: consumption of fruits and vegetables. Nutrition 67-68, 110568.

40. Sanjeevi N, Lipsky L, Liu A et al. (2019) Differential reporting of fruit and vegetable intake among youth in a randomized controlled trial of a behavioral nutrition intervention. Int J Behav Nutr Phys Act 16, 15. 